\title{
Design, Simulation and Control of a Marine Ship Model's Diesel Engine using Python and Matlab/Simulink
}

Fouad Kharroubi (https://orcid.org/0000-0002-1112-7774), Mohammed Fertat (https://orcid.org/0000-00033288-128X), Sanae El Hassani (https://orcid.org/0000-0002-6517-2570), Hassan Ouahmane (https://orcid.org/0000-0001-8723-6590)

Department of Telecommunications, Networks and Computer Science (TRI), LTI Laboratory, National School of Applied Sciences (ENSAJ), Chouaib Doukkali University, El Jadida City, 24002, Morocco. E-mail: fouad.kharroubi@gmail.com

Marine ships engines are kind of huge diesel engines. In fact, the manner of controlling the speed of a ship can impact badly on the financial matters of the machinery operation. Thus, controlling the speed of the marine engines can avoid ships to face dangerous accidents. In purpose to prevent such kind of damages, marine systems simulator have been widely used as numerical tools. In fact, the simulation of speed control systems makes it possible to render the process of controlling the speed of an engine economical and eliminates many risks. In this article, we first present a mathematical formulation to illustrate the rotational velocity process of a ship model's marine diesel engine as well as its PID controller. Secondly, we introduce a novel python's marine simulator which includes a PID controller to govern marine ship model's engines and we compare its results with another PID diesel engine speed controller that we modelled, designed and simulated via Matlab/Simulink. Results of scenarios and experiences which we carried out have shown that the response of the speed control system when using python can be accurate and close to the one of Matlab/Simulink.

Keywords: Marine, Diesel Engine, Ship, Model, Simulation, Python, Matlab, Simulink; Towing Tank Testing, Speed-Control System

\section{Introduction}

For many decades, diesel engines have been extensively utilized in reality as a main power source due to its highest effective efficiency compared to all the other combustion engines. Diesel engine's industry encompasses powers generators, automobiles as well as ships [1]. In fact, marine ships engines are kind of huge diesel engines which require a tough speed control [12].

Furthermore, marine control systems or marine cybernetics is known to be the science about techniques and methods for analysis, monitoring and control of marine systems [2]. In the context of marine diesel engines, the speed control system is an important part of the engine room control and plays an important role in marine automation [3]. In reality, there is always an ultimate need of a reliable control system to regulate the speed of marine diesel engines for safe and efficient operations under different conditions and external load disturbances [4]. In fact, the manner and the degree of controlling the speed of a ship impacts badly on the financial matters and optimization of the machinery configuration and operation [5][10][11][13]. In other words, well governing, monitoring and controlling the speed of the marine diesel engines can avoid ships to face some dangerous accidents such as collision or grounding.

In purpose to study and to prevent such kind of accidents, marine systems simulator have been widely used for years (especially those based on Matlab/Simulink) as numerical tools in system design and analysis, both in academia and in the marine industry [18][19][20]. Indeed, simulation designates the execution of a computer program on a computer or network with a view to simulate a real physical phenomenon. A Marine simulator may use models and parameters of various fidelity and under different working conditions to reconstruct the real physical properties of a dynamic system [2][6]. Thus, the simulation of speed control system is the backbone of any marine systems simulator and it obviously makes it possible to render the process of monitoring and controlling the speed of a marine diesel engines more economical and eliminates human and material risks.

In the context of both the marine engineering or also in the naval architecture, no real full scale ship can be constructed and developed without passing through ship models that will be generally well experimented and tested in towing tanks already constructed for this purpose. Which is also the same adopted approach in the field of ship model testing 
when dealing with marine simulators and more specifically with speed control systems. In fact, ship model testing could be broadly divided into two main families, on one hand there are resistance tests --either in waves or still water-- and on the other, maneuvering and sea keeping tests [7]. The former ones are accomplished in towing tanks, which are lanky water channels where the model is connected to a carriage that tows it along the center of the tank. Oppositely, the latter tests are frequently carried out in the ocean basins [7]. However, commercial ship model testing is expensive, time-consuming and it suffers from scale effects. Defenders of computational fluid dynamics declare that an approach based on numerical simulation provides a flexible milieu to construct, test, and analyse ship system efficiency and performance [8][9]. This allows the simulation environment user to optimize, tune, or test possible changes in the ship design parameters, surrounding environment conditions, investigate different power sources or energy management strategies without conducting experiments each time [8][9].

Thus, the main objective of the presented work is to study, design, simulate and control a speed control system of a marine ship model's diesel engine under two different platforms, the first is the most widely used one which is Matlab/Simulink, and the second one is a novel python's developed simulator. In fact, the simulation of the diesel engine performance will be accomplished through three scenarios. In the first one, the load torque will be fixed to $85 \mathrm{Nm}$ whereas the mass flow of the fuel will be smoothly increased. In the second one, the load torque will be augmented from $70 \mathrm{Nm}$ to $100 \mathrm{Nm}$ while the fuel mass flow is constant during the whole period of the simulation and is equal to 10.To design a PID controller to control the engine rotational velocity by using the mass flow of the fuel as the input variable to the system and to simulate the performance of this PID controller for a constant load torque of $85 \mathrm{Nm}$ and make the engine rotational velocity reach $2000 \mathrm{rpm}$ will be the subject of the third simulation.

\section{The Mathematical Model of our Marine Ship Model's Diesel Engine Speed-Con- troller System}

In this work, a four cylinder diesel marine will be simulated via this first ordinary differential equation:

$$
\frac{d N}{d t}=\frac{60}{2 \pi} \frac{\tau_{e}-\tau_{l}}{I_{e}}
$$

Notice that $\mathrm{N}$ is the engine rotational velocity $[\mathrm{rpm}], \tau_{\mathrm{e}}$ and $\tau_{\mathrm{l}}$ are engine and load torques respectively. $\mathrm{I}_{\mathrm{e}}$ is the engine moment of inertia. The engine torque is calculated as this:

$$
\tau_{e}=\frac{P_{m e} V_{d}}{v 2 \pi}
$$

Where

$$
P_{m e}=e P_{m f}-P_{m r}
$$

And

$$
P_{m f}=\frac{H_{u} m_{f}}{V_{d}} ; \quad H_{u}=45 M j / K g ; m_{f}=\frac{1}{c y l} \frac{W_{f}}{\frac{N}{60}}
$$

Since it is four cylinder diesel engine then $\mathrm{cyl}=$ $4, V_{\mathrm{d}}$ is the displacement volume of the engine, $P_{m e}$ is the mean effective pressure, $P_{m f}$ is the mean fuel pressure, $P_{m r}$ is the mean friction pressure, $\mathrm{m}_{\mathrm{f}}$ is the mass of the fuel in a cylinder during a cycle and $H_{u}$ is the fuel calorific value. $v$ is taken 1 for two stroke engines and 2 for four strike engines. $W_{f}$ is the mass flow of the fuel. The initial condition of the engine rotational velocity is $1500 \mathrm{rpm}$.

$e$ is a coefficient used for the calculation of the mean effective pressure $P_{m e}$ using the mean fuel pressure $P_{m f}$ and the mean friction pressure $P_{m r}$. The value of the coefficient $e$ is calculated with the formula shown in the following table, using the values of the displacement volume $V_{d}$, the engine moment of inertia $I_{e}$, and the mean friction pressure $P_{m r}$. Fig. 1 shows the main Graphical User Interface (GUI) of our novel marine ship model's diesel engine simulator which will help the user to set up freely these simulation's parameters. The values of $V_{d}, I_{e}, e$ and $p_{m r}$ are given in the table below:

Tab. 1 The values of parameters

\begin{tabular}{|c|c|c|c|}
\hline $\boldsymbol{V}_{\boldsymbol{d}}\left[\boldsymbol{m}^{\mathbf{3}}\right]$ & $\boldsymbol{I}_{\boldsymbol{e}}\left[\mathbf{k g m}^{\mathbf{2}}\right]$ & The Coefficient $\boldsymbol{e}$ & $\boldsymbol{p}_{\boldsymbol{m} \boldsymbol{r}}\left[\boldsymbol{K} \boldsymbol{p}_{\boldsymbol{a}}\right]$ \\
\hline 0.0023 & 0.2750 & $110 \boldsymbol{V}_{\boldsymbol{d}}\left[\boldsymbol{m}^{\mathbf{3}}\right]+\mathbf{0 . 0 1}^{\boldsymbol{I}_{\boldsymbol{e}}\left[\mathbf{k g m}^{2}\right]}-\frac{\boldsymbol{p}_{\boldsymbol{m r}}\left[\mathbf{K p}_{\boldsymbol{a}}\right]}{\mathbf{1 7 5 0}}$ & 145 \\
\hline
\end{tabular}

The interested reads are referred to [14][15][16][17] for more examples of mathematical models and formulations of marine diesel engines and their corresponding speed control systems. 
Simulation

\section{Please, enter your data \& choose the case that you want :}

$\mathrm{m}^{\wedge} 3$

\section{Time (define the destination it will begin from 0 ) : \\ 10 \\ PID:controller \\ 3 Marine Diesel Engines Simulation and Control}

Displacement volume of the engine: 0.0023

\section{stroke engine:}

number of cylinders:

The fuel calorific value:

The engine moment of inertia:

Mean friction pressure:

Initial condition of the engine rotational velocity:

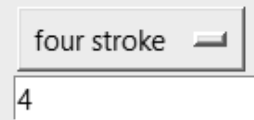

45

0.275

145

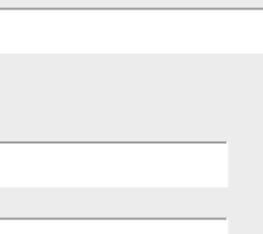

\section{$\mathrm{Mj} / \mathrm{kg}$}

$\mathrm{kg} \cdot \mathrm{m}^{2}$

kpa

$\begin{array}{ll}1500 & \text { rpm (rotation par minute) } \\ 10 & \text { seconds (s) }\end{array}$

Fig. 1 The main GUI of our novel marine ship model's diesel engine simulator developed using python

- Simulation 1: In this first scenario we use a constant load torque which is equal to $85 \mathrm{Nm}$ and a smoothly increasing mass flow of the fuel ;

As it was explained above in the introduction part, in this scenario the load torque will be fixed to $85 \mathrm{Nm}$ during the whole period of simulation which is equal to 10 seconds (Fig. 3-D), whereas the mass flow of the fuel will be smoothly increased according to a slope that can be chosen by the user otherwise its default value is 1 while using our python program, however when using Matlab/Simulink a ramp block has been used for a smoothly generation of the mass flow of the fuel which rises from 0 to 10 in 10 seconds (Fig.3-C).

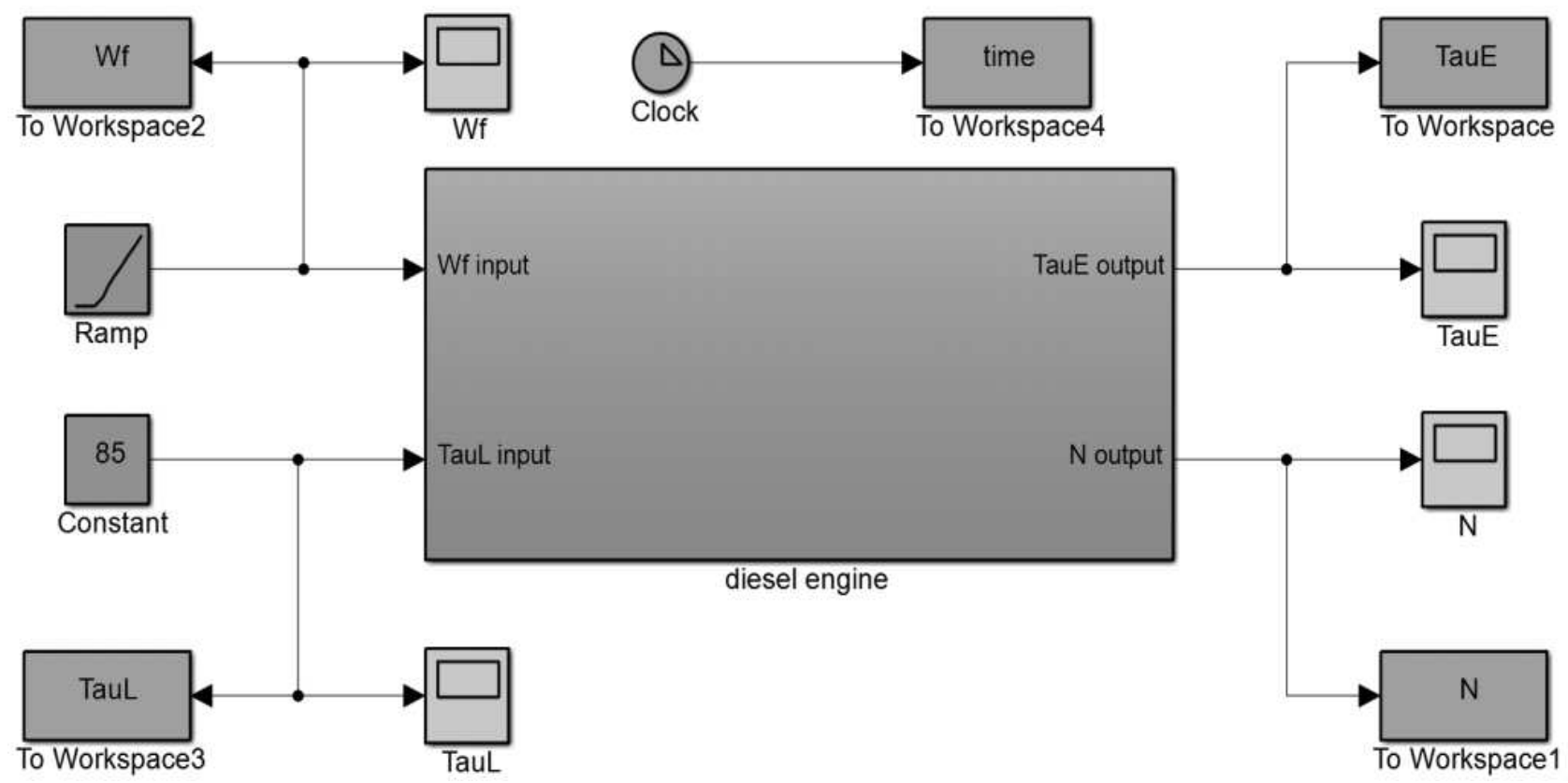

Fig. 2The equivalent Matlab/Simulink model of the first simulation 
In terms of engine's speed, Fig.3-A shows that in the beginning of the period of the simulation, when using Matlab/Simulink, the speed of the engine drops from the initial speed which is $1500 \mathrm{rpm}$ to around $300 \mathrm{rpm}$. After about 5 seconds of the beginning of the simulation, the speed increase again to1500 rpm because of the increase of the mass flow of the fuel. The speed of the engine keeps rising after that and reaches the value of $2622 \mathrm{rpm}$ at the end of the simulation. However, when using our novel python's simulator the speed of the engine drops a little bit from the initial speed which is $1500 \mathrm{rpm}$ to around 1450 rpm and 3 seconds later the speed increases steadily

\section{(A) The Engine Speed (T-N)}

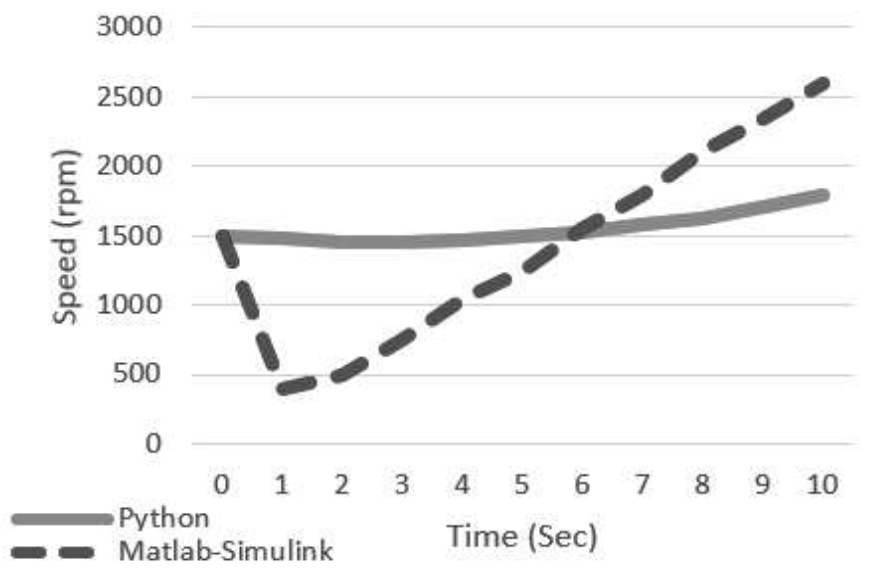

(C) The Mass Flow of the Fuel (T-Wf)

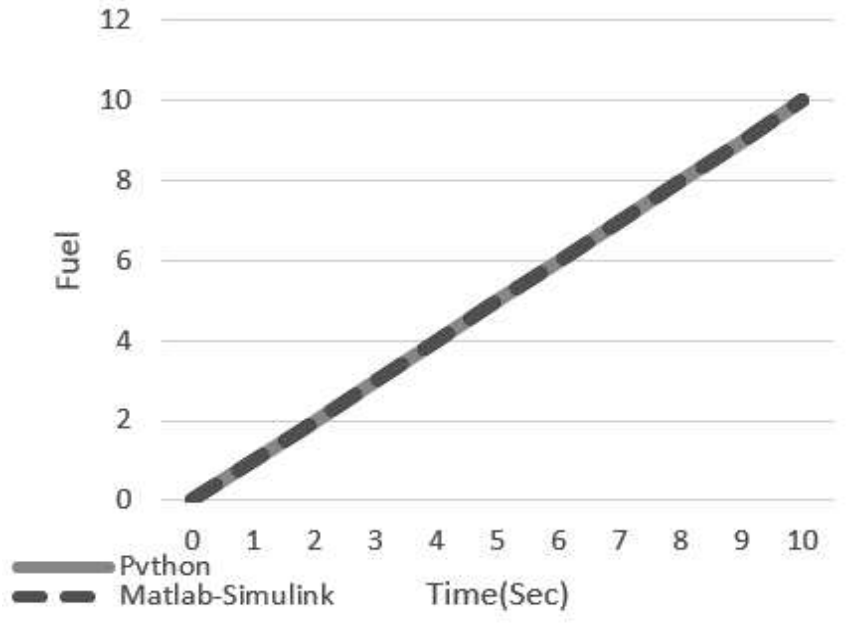

again to reach the value of $1800 \mathrm{rpm}$ at the end of the simulation. In relation with the engine torque (Fig3. B), for both curves the Matlab/Simulink one as well as the one generated via the python simulator increase with the rise of the fuel mass flow. In fact, for the first 5 seconds the Matlab's curve representing the engine torque increases rapidly and with higher value comparing to the one of python. However, starting from the second number 6 both curves show almost the same behaviour by reaching the value of $95 \mathrm{Nm}$ and staying almost stable at this value till the end of the simulation.

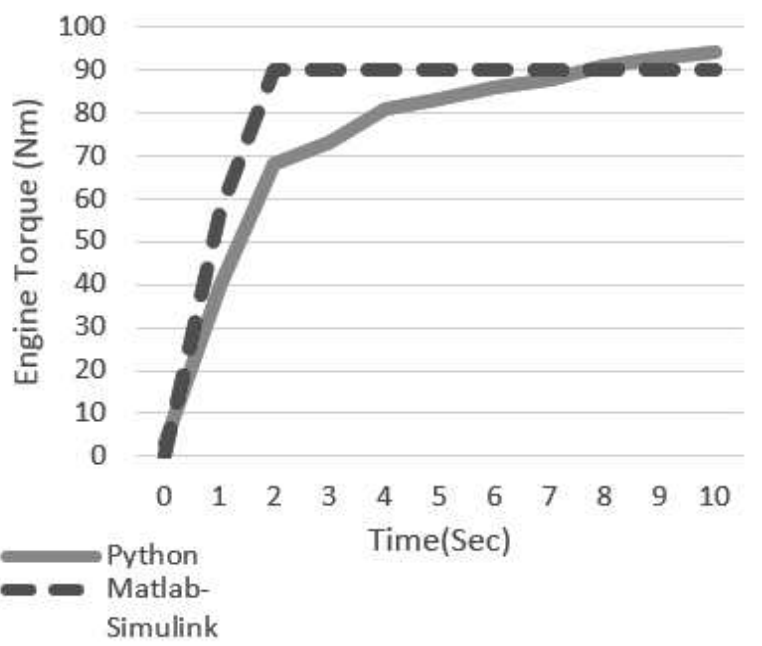

(D) The Load Torque (T-TL)

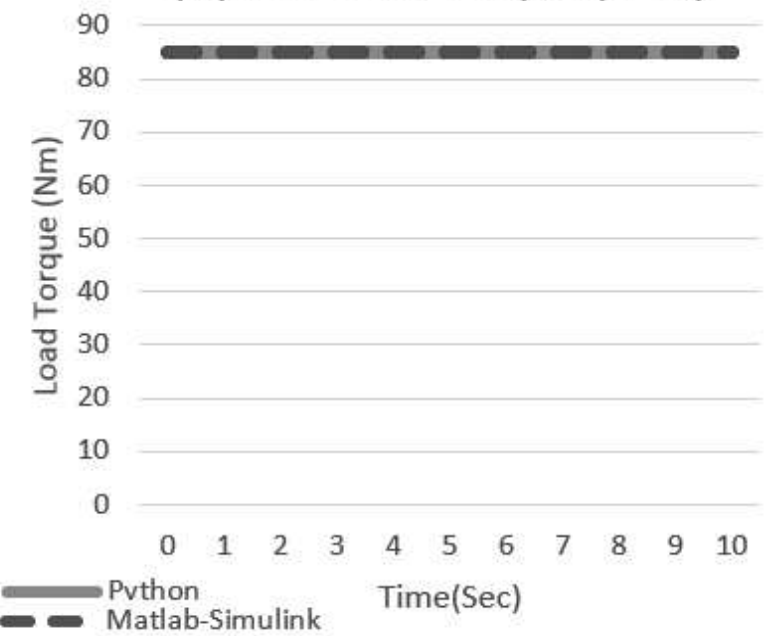

Fig. 3 Simulation results under the first scenario using python and Matlab/Simulink

- Simulation 2: In this second scenario we use a smoothly increasing load torque and a constant mass flow of the fuel which is equal to 10 ;

In this second scenario, the fuel mass flow $\boldsymbol{w}_{\boldsymbol{f}}$ is equal to 10 (Fig.5-C) and will be constant during the whole period of the simulation, whereas the load torque will be generated increasingly from $70 \mathrm{Nm}$ to $100 \mathrm{Nm}$ in $10 \mathrm{~s}$ with a slope equal to 3 (Fig.5-D). In the case of Matlab/Simulink the load torque is generated with the use of the ramp block while when using Python it is ensured via an increased function that rises the target output value according to the personal slope that can be entered freely by the user through the GUI. 


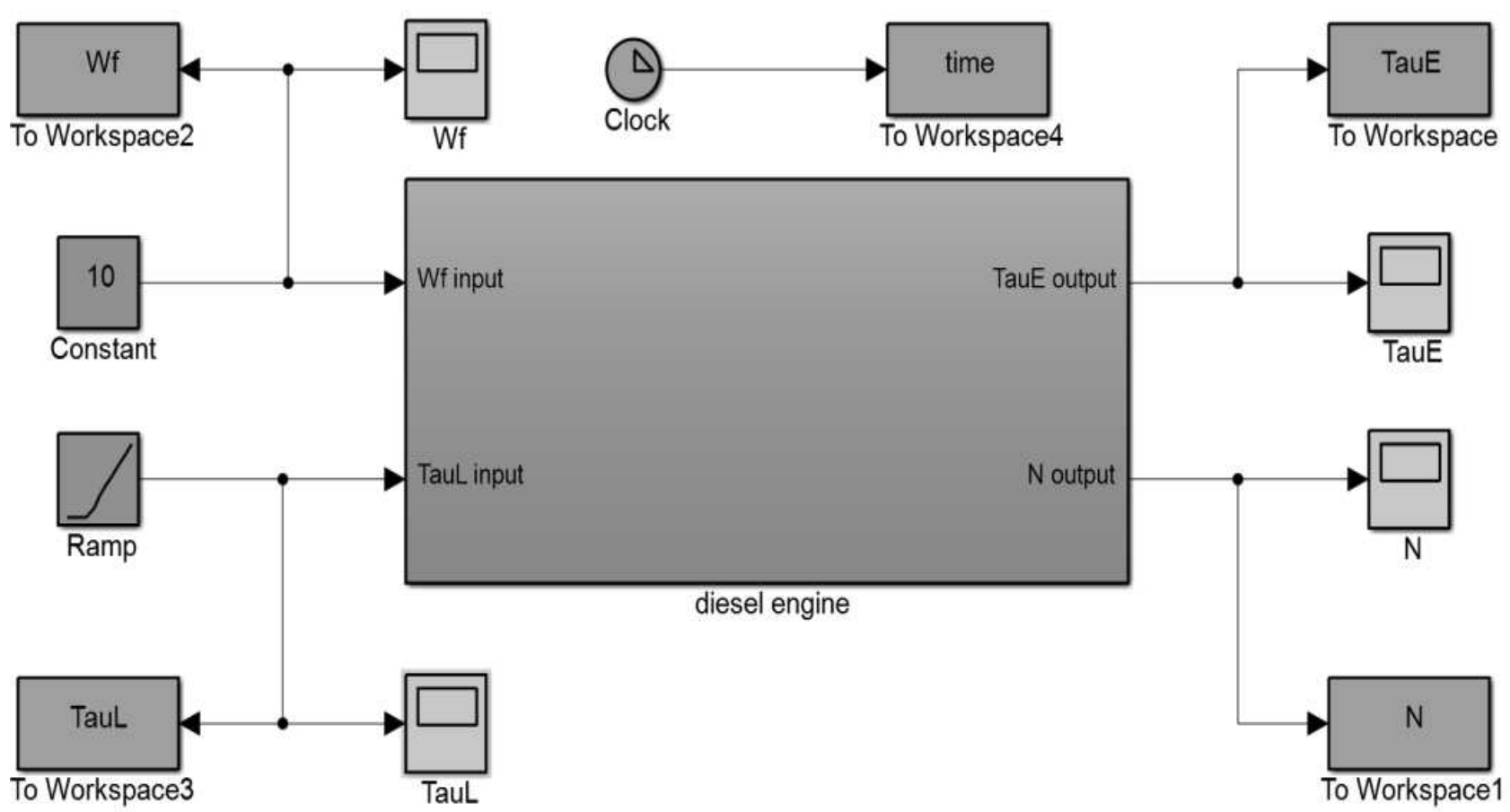

Fig. 4 The Equivalent Matlab/Simulink model of the second simulation

(A) The Engine Speed (T-N)

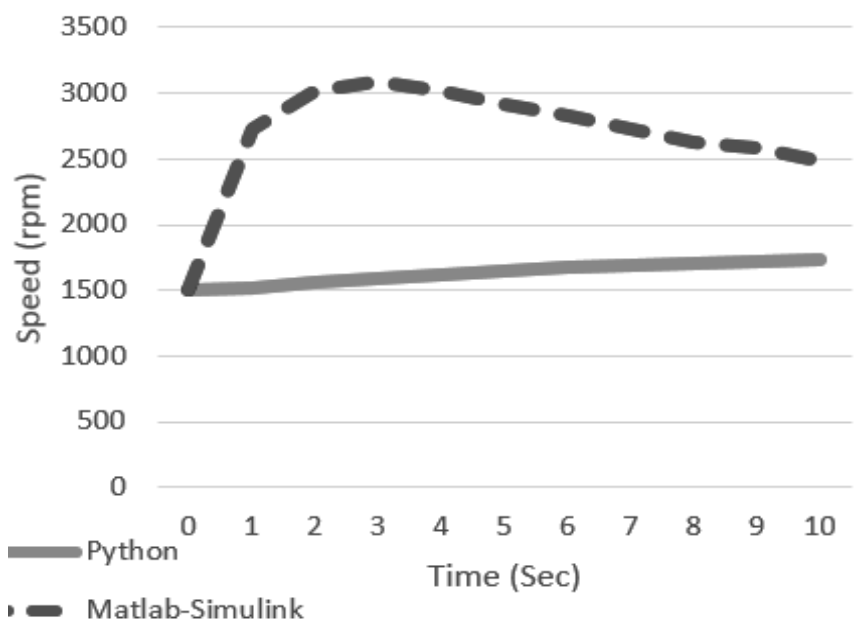

(C) The Mass Flow of the Fuel (T-Wf)

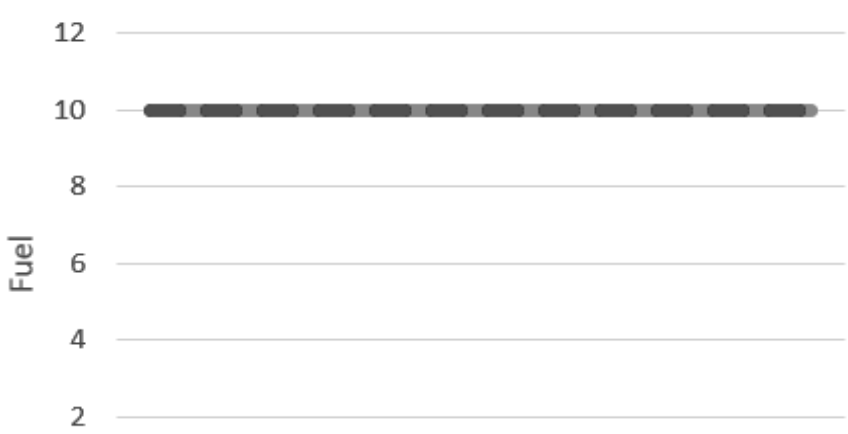

0

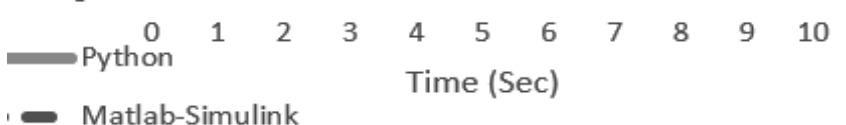

Fig. 5 Simulation results under the second scenario using Python and Matlab/Simulink
(B) The Engine Torque (T-E)

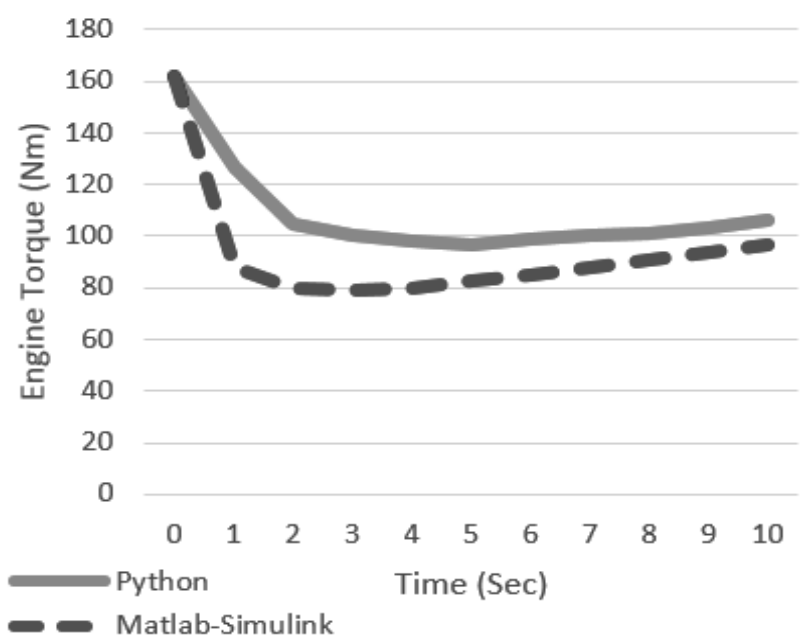

(D) The Load Torque

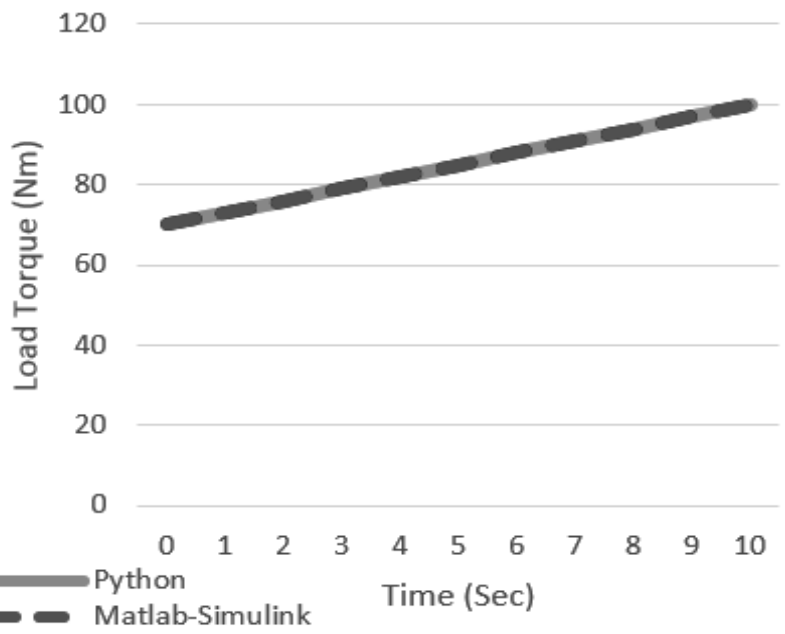


Concerning the engine's speed (see Fig. 5-A), in the first 3 seconds, when using Matlab/Simulink, the speed of the engine increases from $1500 \mathrm{rpm}$ to a maximal value of about $3092 \mathrm{rpm}$. After that the speed of the engine starts decreasing and reaches the value of $2484 \mathrm{rpm}$ at the end of the simulation. Meanwhile, the python engine's speed curve rises steadily from 1500 $\mathrm{rpm}$ to reach the value of $1800 \mathrm{rpm}$ at the end of the simulation. In connection with the engine torque (Fig 5. B) in the first 3 seconds, both line graphs show almost the same behaviour, in fact whether it is for Matlab/Simulink curve or python's one the engine torque is decreasing from the value of $162 \mathrm{Nm}$ to the value of $78 \mathrm{Nm}$ and from $162 \mathrm{Nm}$ to $90 \mathrm{Nm}$ respectively due to the fact that the speed of the engine is rising rapidly during this period. After that, the engine torque starts rising for both line graphs because the speed of the engine is decreasing. When using Matlab/Simulink the torque reaches the value of 97
$\mathrm{Nm}$ at the end of the simulation whereas it reaches the value of $105 \mathrm{Nm}$ in while using Python's simulator.

- Simulation 3: In this third simulation we use a constant load torque which is equal to 85 $\mathrm{Nm}$ and a mass flow of the fuel controlled by a PID controller;

The main idea behind this third scenario, is to use a PID controller as a marine diesel engine speed governor to reach the speed of $2000 \mathrm{rpm}$ at the end of the simulation. In fact, as it was explained in [3] the marine diesel engine speed control system is an important part of engine room control and plays an important role in marine automation. In this work, we adopted the traditional PID control method since it is the most extensively deployed in the marine diesel engine speed governor and which has the advantages of simple structure, good adaptability and strong stability [3].

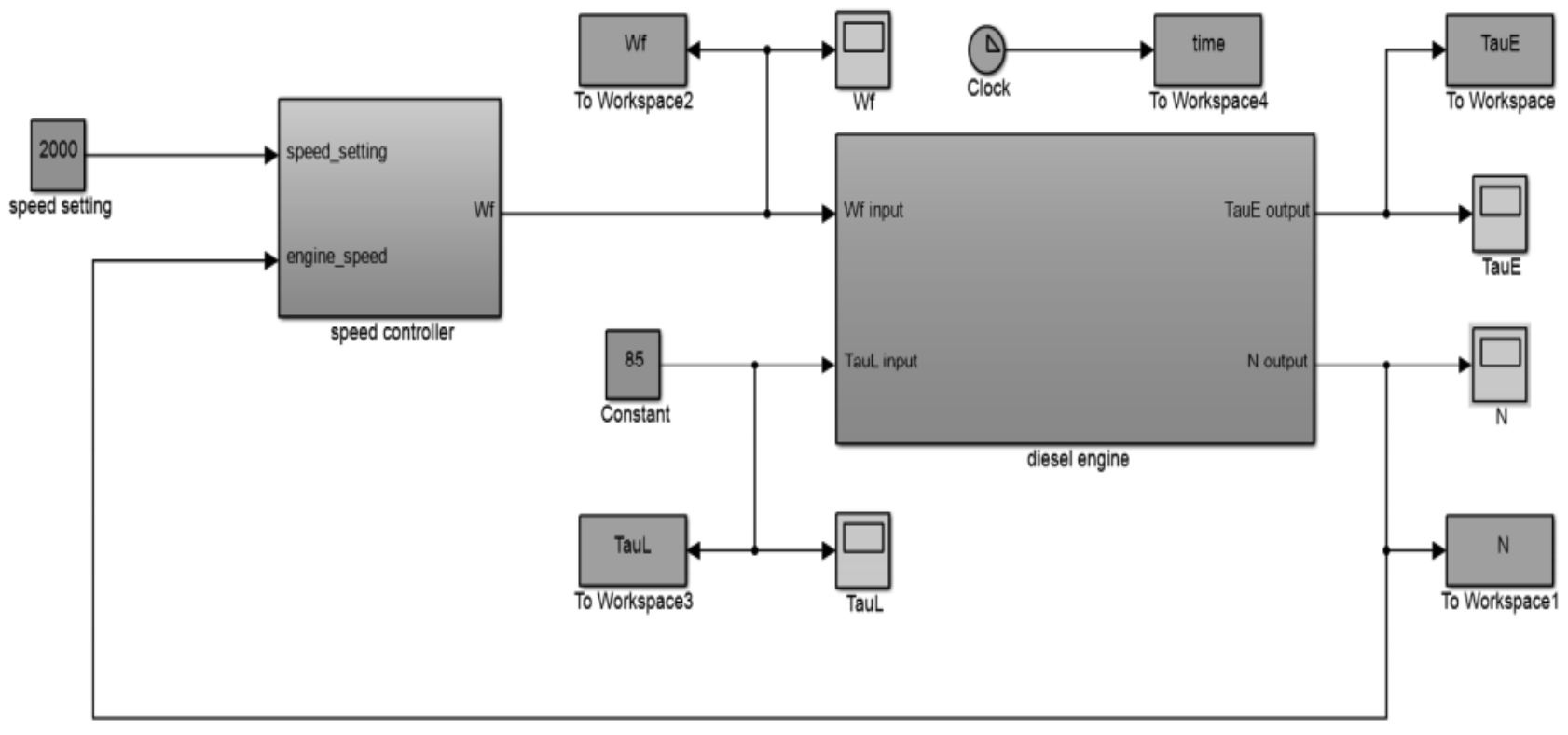

Fig. 6The Equivalent Matlab/Simulink. Model of the third Simulation

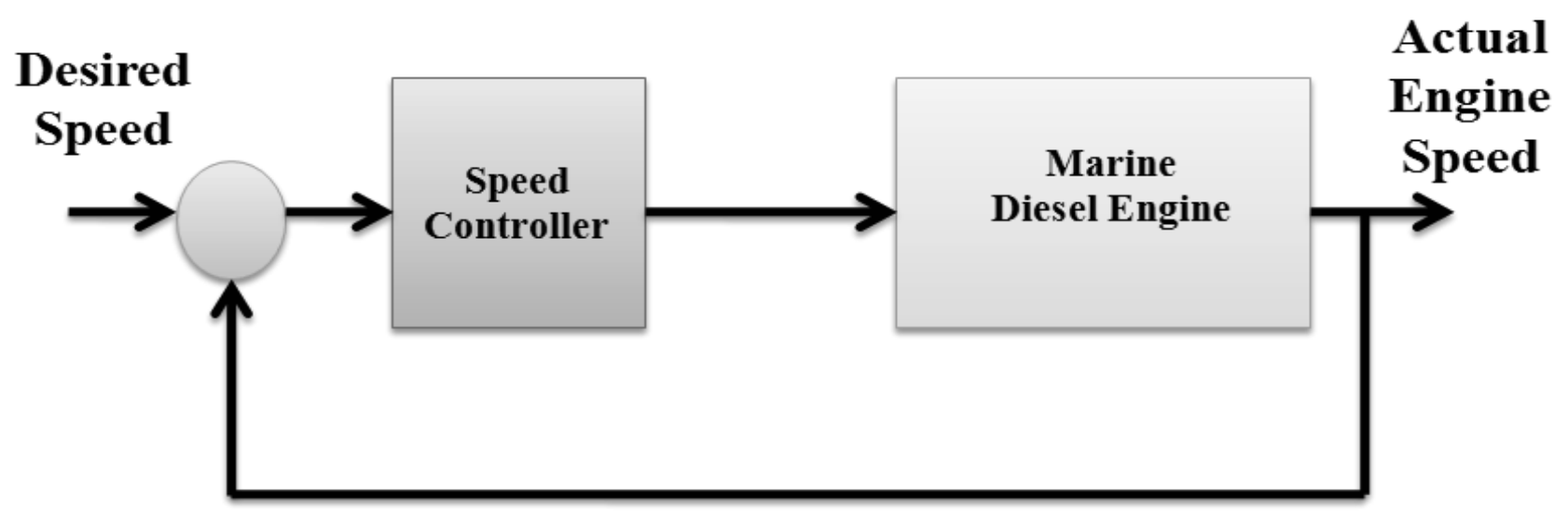

Fig. 7 Speed control system of a marine diesel engine

Our general marine diesel engine speed control systems is presented in Fig. 7 and it is equivalent using
Matlab/Simulink is shown in Fig.8.

For the purpose of simulating and comparing our 
marine diesel engine speed control system using Python and Matlab/Simulink, we developed and implemented a PID controller's algorithm via this simplified

$$
w_{f_{\text {final }}}=w_{f_{\text {initial }}}+K_{p} \Delta \boldsymbol{N}+K_{i} \int_{0}^{t} \Delta \boldsymbol{N d t}+K_{d} \frac{d \Delta N}{d t}
$$

Where $: \Delta N=[($ Desired_Engine_Speed $)-($ Actual_Engine_Speed $)]$

and where $K_{p}, K_{i}$ and $K_{d}$ all non negative, indicate the coefficients for the proportional, integral and derivative terms respectively. $\mathrm{w}_{\mathrm{f}_{\text {final }}}$ is the produced fuel mass flow that will be injected to the marine diesel engine, whereas $\mathrm{w}_{\mathrm{f}_{\text {initial }}}$ is its initial value that will be injected to the controller. While using Matlab/Simulink, the optimal parameters of our PID controller are: $K_{p}=2785 * 10^{-5}, K_{i}=2000 * 10^{-5}, K_{d}=$ $-114 * 10^{-5}$. However, when using our python simulator we set the PID controller with these parameters: $K_{p}=5708, K_{i}=290, K_{d}=-2970$.
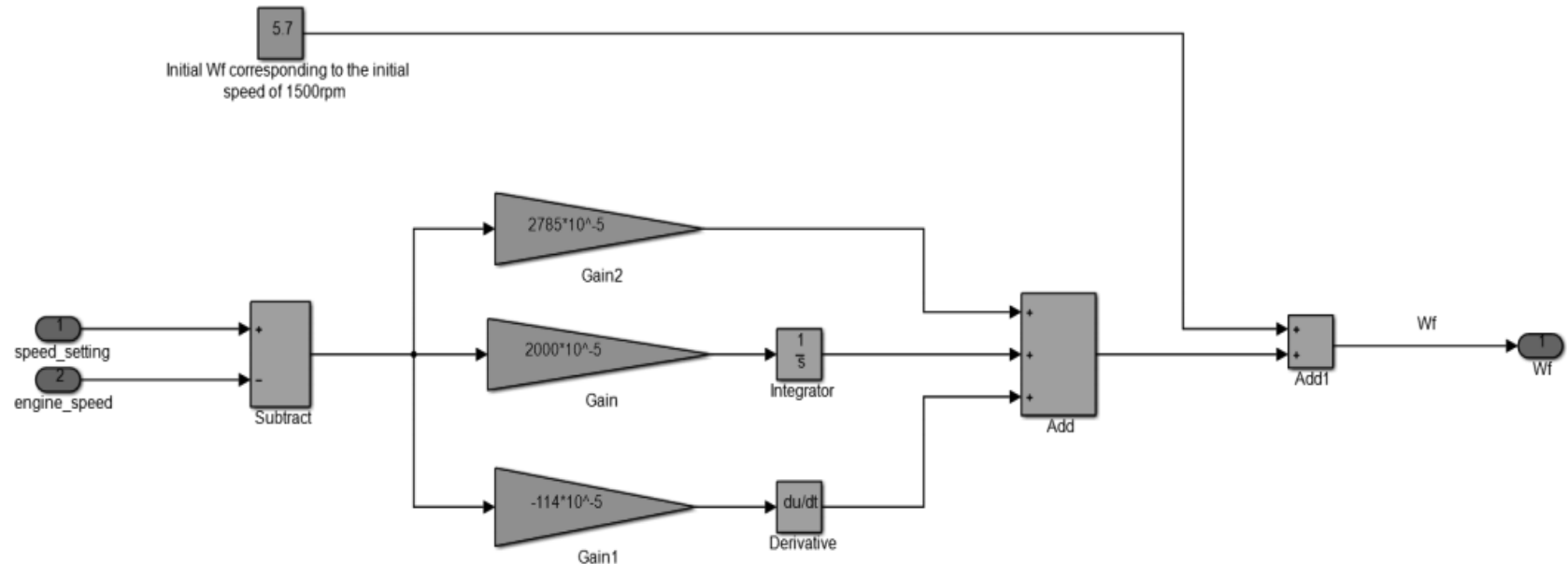

Fig. 8 The Internal design of our speed control system of marine diesel engine using Matlab/Simulink

(A) The Engine Speed (T-N)

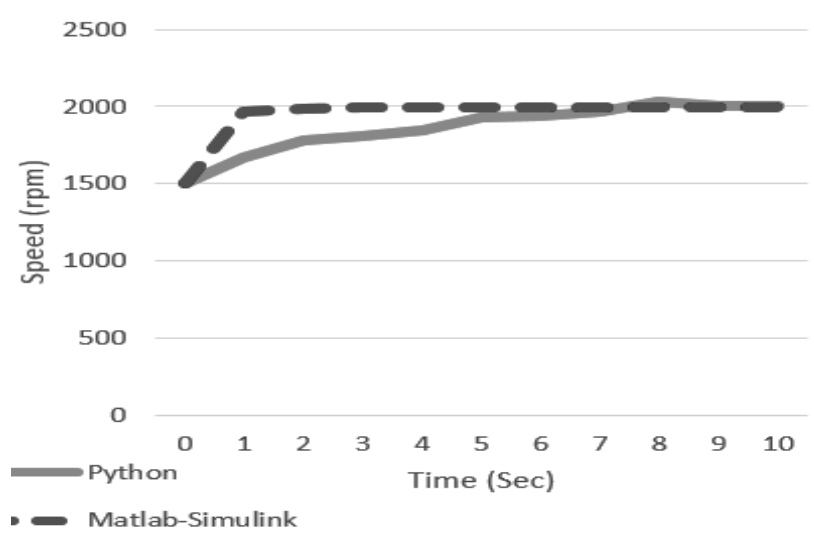

(C) The Mass Flow of the Fuel (T-Wf)

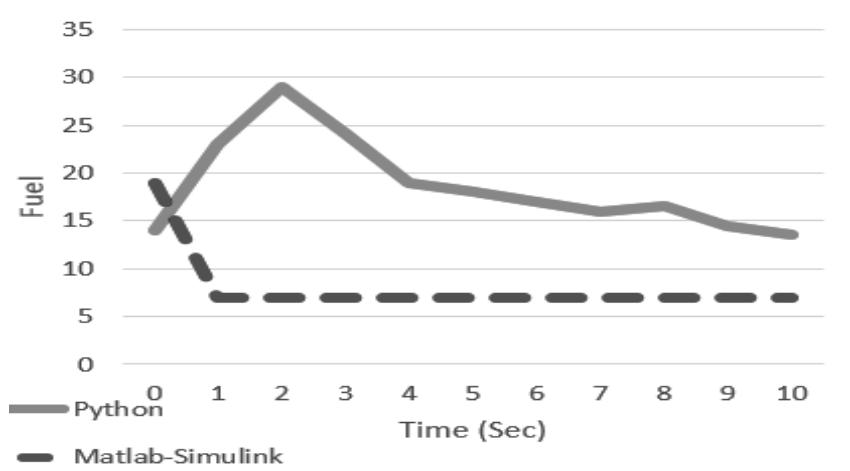

(B) The Engine Torque (T-TE)

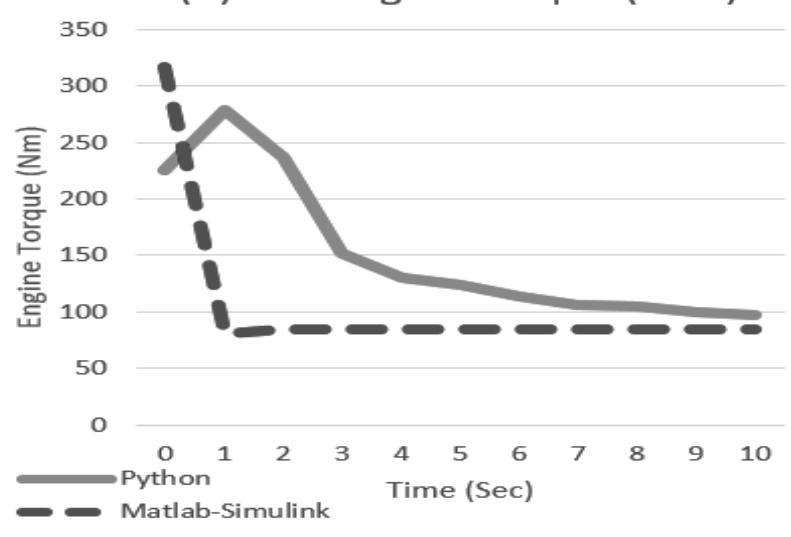

(D) The Load Torque (T-TL)

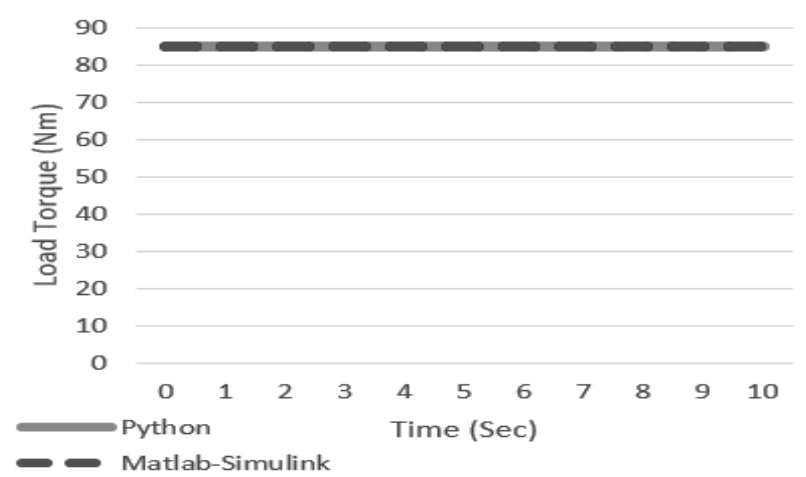

Fig. 9 Simulation results under the second scenario using Python and Matlab/Simulink 
In this third scenario, whether using Matlab/Simulink or our novel python's simulator the load torque is constant and it is equal to $85 \mathrm{Nm}$ during the whole period of the simulation (see Fig.9-D). Furthermore, Fig.9-C shows the shape of the fuel mass flow $\mathrm{w}_{\mathrm{f}}$ generated by the PID speed controller after its tuning. In fact, while using Matlab/Simulink, the initial value of $\mathrm{w}_{\mathrm{f}}$ is 19 which drops to the value of 7 after the first second and remains constant until the end of the simulation. However, while using python the fuel mass flow $w_{f}$ rises to about 30 during the first two seconds of the time of the simulation then it declines gradually as times of the simulation goes by to arrive to the value of 13 and stays almost stable at the end of the simulation (see Fig.9-C). In terms of engine's speed, Fig.9-A shows that either using Matlab/Simulink or our python's simulator the controller has proven that it is well tuned since both curves representing the engine's speed reach the value of $2000 \mathrm{rpm}$ after few seconds and stay stable at it. Finally, Concerning the engine's torque, for both curves the Matlab/Simulink (see Fig.9-B) one as well as the one generated via the python simulator drop after few seconds of starting the simulation because the engine speed is rising, then it becomes constant at the end of the simulation since both the engine speed $N$ and the fuel mass flow $w_{f}$ are constants as well.

\section{Conclusion and Perspectives}

In this article, we mathematically modelled a four stroke four cylinder marine ship model's diesel engine with a PID controller and simulated them via two different methods. In the first one, we developed a novel marine ship model's diesel engine simulator using python language capable of letting the user to enter the different parameters of the simulation and visualizing as well as plotting the corresponding results. However in the second method we developed the same diesel engine model and its PID controller but this time with the help of Matlab/Simulink environment. In order to validate the efficiency and the accuracy of our developed marine ship model's diesel engine and its PID controller we compared the simulation results of both the novel python's simulator and those found through Matlab/Simulink environment.

This conducted comparison wouldn't have a meaning without experimenting the proposed diesel engine's model and its PID controller under different scenarios and tests. In fact, the accuracy of the final results have shown that our novel python's simulator can also be a promising interactive tool for controlling and simulating marine ship model's diesel engine the same as the famous Matlab/Simulink platform. As further perspectives of this work, we are planning to optimize the PID controller's parameters using a Ge- netic Algorithm (GA) and an Evolutionary Programming (EP) algorithm, which will considerably improve the diesel engine control effect and performance. Additionally, the real-time control of the marine diesel engine speed and predicting the ship power and resistance can be also modelled, investigated and injected into our novel python's simulator.

\section{Acknowledgment}

The first author would like to thank both, firstly Dr.Kamal Kharroubi from the Department of Naval Architecture and Marine Engineering, Istanbul Technical University, Istanbul, Turkey for introducing the problem and his help and advice for the Matlab/Simulink part, secondl our ENSAJ School's Students: Ms. BOUKHARS Meryem and Ms. BERKIA Fatima Zahra for their contribution during the coding phase of our novel python's model's diesel engine controller and simulator.The first author, however bears full responsibility for the paper.

\section{References}

[1] JIANG, J., (1993). Optimal gain scheduling controller for a diesel engine. In: IEEE Conference on Control Applications, Vancouve, British Columbia, Canda, September 13-16.

[2] ASGEIR, J, S. (2013). Marine Control Systems Propulsion and Motion Control of Ships and Ocean Structures. In: Lecture Notes. Department of Marine Technology. Norwegian University of Science and Technology. Report UK-13-76

[3] XIAOQUN, S., YUXIANG S. (2012). Marine Diesel Engine Speed Control System Based on Fuzzy-PID. In: Applied Mechanics and Materials Vol, 152-154pp 1589-1594.

[4] SHUO, X., XIUMIN, C., CHENGUANG, L., MAO Z. (2018). Marine diesel engine speed control based on adaptive state-compensate extended state observer-backstepping method. In: Proc IMechE Part I: J Systems and Control Engineering 1-15.

[5] NAEIM, F., LIU S. (2011). Speed control systems on marine diesel engine with genetic algorithm. In: International Journal of Engineering Science and Technology (IJEST) Vol. 3 No. 7. ISSN : 0975-5462.

[6] SORENSEN, A, J., PEDERSEN, E., SMOGELI, O. (2003). Simulation-Based Design and Testing of Dynamically Positioned Marine Vessels. In: Proceedings of International Conference on Marine Simulation and Ship Maneuverability, MARSIM'03. 
[7] PENA, F,L., GONZALEZ, M,M., DEIBE, A., PENA, D., ORJALES, F. (2013).An Autonomous Scale Ship Model for Towing Tank Testing. In: Proceedings of the 7th IEEE International Conference on Intelligent Data Acquisition and Advanced Computing Systems: Technology and Applications, Pp. 25-29.

[8] AMEEN, M,B., ALEXANDER, B, P., STEPHEN, R, T., PHILIP, A, W. (2019). Experimental testing and simulations of an autonomous, self-propulsion 2 and self-measuring tanker ship model. In: Ocean Engineering.

[9] NEILSON, J., TARBET, R., (1997). Propulsion system simulations: Making the right choice for the application. In: Naval engineers, 434 journal 109 (5), 83-98.

[10] NAEIM, F. (2012). Genetic Algorithm and Fuzzy Tuning PID Controller Applied on Speed Control System for Marine Diesel Engines. In: Research Journal of Applied Sciences, Engineering and Technology 4(21): 4350-4357.

[11] HAIRUI, W., LU, W., YONGYI, L., HONGWEI Y. (2019). Research on Engine Speed Control System Based on Fuzzy Adaptive PID Controller. In: Manufacturing Technology, Vol. 19, No. 6.

[12] CHENG, M., ENZHE, S., GUOFENG, Z., CHONG, Y. (2018). Study on Intelligent Speed Control Algorithm for Diesel Engine. In: 14th International Naval Engineering Conference \& Exbibition. Conference Proceedings of INEC 2 - 4 October.

[13] TIEN, A, T. (2018). The Optimization of Marine Diesel Engine Rotational Speed Control Process by Fuzzy Logic Control Based on Particle Swarm Optimization Algorithm. In: Future Interne, MDPI.10,99.
[14] RAJENDRA, P, S., RAJOO B. (2018). A Mathematical Model of Marine Diesel Engine Speed Control System. In: J. Inst. Eng. India Ser. C. 99(1):63-70.

[15] YUANQING, W., GUICHEN, Z., ZHUBING, S., QI, W., JUAN, S., HONGYU, Q. (2020). In: Finite-time active disturbance rejection control for marine diesel engine. Applied Mathematics and Nonlinear Sciences 5(1) 35-46.

[16] RUNZHI, W., XUEMIN, L., JIGUANG, Z., JIAN, Z., WENHUI, L., YUFEI, L., WENJIE, F., XIUZHEN, M. (2018). Speed Control for a Marine Diesel Engine Based on the Combined Linear-Nonlinear Active Disturbance Rejection Control. In: Hindawi Mathematical Problems in Engineering Volume 2018, Article ID 7641862, 18 pages.

[17] RAFAEL, V, K., JAMES, J, R., ROSANA, M, R. (2017). Small boats as vectors of marine invasion: experimental test of velocity and desiccation as limits. In: Mar Biol, 164:27.

[18] PETRU M., MLYNEK J., MARTINEC T. (2018). Numerical Modelling for Optimization of Fibres Winding Process of Manufacturing Technology for the Non-Circular Aerospaces Frames. In: Manufacturing Technology, Vol. 18, pp. 90-98.

[19] SEGLA S., KAMPO J. (2018). The Role of Modelling of Road Unevennesses in Vehicle Dynamics. In: Manufacturing Tecbnology, Vol. 18, pp. 124-129.

[20] SAPIETA M., SULKA P., SVOBODA M. (2018). Using a Numerical Model to Verification of Thermoelastic Analysis of Flat Specimen. In: Manufacturing Technology, Vol. 18, pp. 482-486. 